\title{
Valoración de la formación recibida usando un perfil de referencia basado en competencias profesionales
}

\author{
Valuation the formation using a profile of reference based on professional competences
}

Mónica Maldonado Rojas

Facultad de Ciencias de la Salud. Universidad de Talca - Chile

Introducción: La formación profesional está hoy en día promoviendo la implementación de opciones educativas basadas en modelos por competencias. El presente trabajo tuvo como propósito establecer un perfil de referencia basado en competencias profesionales para la carrera de Tecnología Médica de la Universidad de Talca y usando éstas como indicadores, conocer la auto percepción que tienen los egresados respecto del grado en que fueron adquiridas durante su formación.

Material y métodos: Se realizó una investigación de tipo exploratoria, mediante una encuesta autoaplicada que contenía un conjunto de indicadores que correspondian a competencias establecidas previamente en un perfil de referencia, cuya estructura considera diferentes áreas de desempeño. El perfil fue validado por juicio de expertos, determinando el grado de congruencia a través del coeficiente de Serafine. La construcción de la información se realizó a partir de las repuestas, las que fueron codificadas y representadas en porcentajes y posteriormente analizadas bajo categorías interpretativas.

Resultados: La evaluación que se hace considera el porcentaje de egresados que valoró el logro de las competencias por área de desempeño en los niveles más altos. Los resultados obtenidos fueron: Para el área asistencial el 72,9\%, para el área investigación un $59 \%$, para el área de docencia un $44 \%$, para el área administrativa un $27,1 \%$ y para el área personal-social un $91,3 \%$. Conclusiones: Siguiendo el criterio de categorías interpretativas, el área personal social indica una gran fortaleza de la formación, el área asistencial y el área investigación se encuentran en un nivel satisfactorio y las áreas docencia y administración en niveles medianamente satisfactorio, siendo esta última la gran falencia de la formación. El currículo vigente es adecuado para asegurar el logro de gran número de competencias, pero se debe revisar con el objetivo de incorporar contenidos para el logro de aquellas deficientes.

Palabras claves: Educación médica, perfil profesional, competencias profesionales, evaluación egresados. 
Introduction: The professional formation is today promoting the implementation of educational options based on competences. This has the purpose of establishing a reference profile, based on professional competences for the Medical Technology career of the University of Talca, using them as indicators, to know the self perception which graduate students have, regarding the level acquired during their formation.

Material and method: According to this, an evaluative and descriptive investigation, throughout a self applied survey was carried out. It contained a group of indicators corresponding to previously settled competences in a reference profile where its structure considers different areas, validated by experts, determining the consistency degree through Serafine coefficient. The construction of the information was carried out according to the graduate answers decoded and represented in percentages and later analyzed under interpretative categories. Results: The evaluation considers the percentage of that valued the profile of the competences by area of performance in the highest levels. The obtained results were: For the assistance area $72.9 \%$, the investigation a $59 \%$, the teaching a $44 \%$, the administrative area a $27.1 \%$ and the personal-social area a $91.3 \%$.

Conclusions: The evaluation made by graduate students about their formation reflects the valued given to the skills acquired in their formation the interpretative categories, the personal-social area is highly evaluated, indicating a great formation advantage, the assistance and investigation area are satisfactory. The teaching and administration area fairly satisfactory. However the last one is considered the lowest. Curriculum effective it is adapted to assure the profile of competences but one is due to review with the objective to incorporate contents for the profit of those deficient.

Key words: Medical education, professional profile, professional competences, graduate students evaluation.

\section{INTRODUCCIÓN}

El fenómeno de la globalización, como contexto general, ya se ha impuesto en todos los ámbitos de la sociedad y el educativo no es la excepción. Ante la constante transformación productiva, la vertiginosa innovación tecnológica y la voraz competencia de los mercados globales, la necesidad de relacionar de una manera más efectiva la educación con el mundo del trabajo, es una demanda que deben atender las Instituciones educativas que pretendan mantener la excelencia en su función social de formadores. El formar profesionales realmente capacitados, está hoy en día íntimamente ligado a la noción de aprendizaje como proceso abierto, flexible y permanente ${ }^{1}$. Esta perspectiva conduce a promover la implementación de opciones educativas basadas en los denominados modelos por Competencias. La Educación por Competencias se está convirtiendo claramente en una tendencia que busca dar respuesta a estas nuevas exigencias ${ }^{2}$.

Los programas curriculares tradicionales han sido elaborados con base en características de un diseño instruccional de contenidos, plan de formación ajeno a las expectativas de los estudiantes y los requerimientos de la sociedad, se formulan con el propósito de que tengan perdurabilidad lo que se convierte en una barrera que imposibilita que cambie acorde a las circunstancias, el diseño lo realizan expertos en compañía de unos cuantos docentes y directivos sin involucrar a toda la comunidad educativa, hay fragmentación en la formación porque se establecen áreas cerradas desde lo disciplinar y las asignaturas no tienen contacto entre sí.

Las competencias se proyectan como un enfoque pedagógico y didáctico para mejorar la calidad de la educación, los procesos de capacitación para el trabajo y la formación en las diversas instituciones educativas. A través de ellas, se busca trascender del énfasis que la educación tradicional le ha dado a la memorización de conocimientos descontextualizados, ya que éstas se basan en el análisis y resolución de problemas con sentido para las personas, con flexibilidad, autonomía y creatividad ${ }^{2}$.

El eje principal de la educación por competencias es el desempeño entendido como la instrumentación concreta de los recursos que pone en juego el individuo cuando lleva a cabo una actividad. Esta premisa pone énfasis en el uso o manejo que el sujeto hace de lo que sabe, en condiciones específicamente concretas en las que el desempeño sea relevante y no tanto en el conocimiento aislado y abstracto que posee. Lo importante no es sólo la posesión de determinados conocimientos, sino el uso que se haga de ellos y este criterio obliga a las instituciones educativas a replantearse el significado de "formación". El objetivo es, formar estudiantes capacitados para una vida profesional versátil. Con este tipo de cualidades, los egresados podrán incorporarse más fácilmente a procesos 
permanentes de actualización, independientemente del lugar en donde se desempeñen.

En el plano del diseño curricular, las competencias aportan una perspectiva que tiene impacto directo en el mejoramiento de la calidad de la educación. Cada competencia viene a ser un aprendizaje complejo que integra conocimientos, habilidades, aptitudes, valores y actitudes. Así entendida, se constituye en un dispositivo metodológico de construcción de los perfiles profesionales y disciplinarios, discusión que debe ser involucrada en el diseño y rediseño de los programas, con la intención de mejorar la pertinencia de los modelos curriculares, en relación con los requerimientos cambiantes de la sociedad en general y del mundo del trabajo en particular ${ }^{3}$.

La Salud Pública como una forma de ejecutar las políticas nacionales de mejorar la calidad de la salud del país, debe preocuparse, entre otras cosas, de la calidad de los egresados de las escuelas formadoras de profesionales del área de Salud, las cuales deben cumplir con su responsabilidad social de lograr que sus egresados posean un perfil profesional de la máxima calidad posible, dado que la educación médica tiene un valor estratégico fundamental para la eficacia del sistema de salud, la economía y la calidad de vida de las personas ${ }^{4}$.

Por otra parte, los sistemas educativos y de formación profesional están llamados a responder al desafío que plantea una nueva cultura de trabajo. Esta nueva cultura de trabajo, está determinada por los sistemas de producción dominantes en el mercado mundial que establecen el tipo de formación y calificación que deben tener los profesionales para insertarse en los mercados de trabajo en las que se requiere de un conjunto de nuevas competencias cognitivas, sociales y tecnológicas ${ }^{5}$.

En otro contexto, una buena parte de las instituciones formadoras de profesionales del área de salud, su actitud evaluatoria ha ido transitando de la autocomplacencia a la autocrítica ${ }^{6,7}$. La evaluación tiene relación directa con la calidad, la cual puede ser definida como "propiedad o conjunto de propiedades inherentes a una cosa, que permiten apreciarla como igual, mejor o peor que las restantes de su especie" ${ }^{11}$.

Dada la necesidad de garantizar a la sociedad, un servicio profesional de calidad, es necesario desarrollar procesos de evaluación de los egresados. En el contexto de las múltiples y variadas estrategias que se desarrollan para evaluar la calidad de los egresados, destaca la que se realiza desde la perspectiva del egresado ${ }^{7}$. Todos los conocimientos y aptitudes adquiridos pueden ser evaluados como reconocimiento de competencias profesionales, las cuales pueden ser verificadas en términos de capacidades acumuladas por el alumno, al término de su currículum de formación, ya que existe preocupación manifiesta por las competencias que han de adquirir los jóvenes para posibilitar una transición efectiva a la vida activa9 ${ }^{9}$. Bunk, considera que tiene competencia profesional "quien dispone de los conocimientos, destrezas y aptitudes necesarios para ejercer una profesión, puede resolver problemas profesionales de forma autónoma y flexible y está capacitado para colaborar en su entorno profesional y en la organización del trabajo"10.

Una forma de evaluar si los nuevos profesionales tienen las competencias requeridas en el nuevo modelo de formación del profesional de la salud, sugerido por la Organización Panamericana de la Salud, sería evaluar a los alumnos recién terminado su programa educativo en los que se asume poseen la dotación inicial definida como un conjunto de conocimientos, lenguajes, metodología, habilidades y destrezas de carácter básico, fundamentales, indispensables y esenciales que se presupone constituyen el suficiente para iniciarse en la práctica de una profesión. En síntesis, se destina medir y evaluar la formación básica que proporciona la entidad educativa ${ }^{11}$.

Los objetivos planteados en este estudio fueron establecer un perfil profesional basado en competencias que abarque las áreas del quehacer de la Tecnología Médica y luego a partir de la autopercepción de los egresados, hacer un diagnóstico del grado de manifestación respecto de las competencias adquiridas durante la formación en la Universidad de Talca.

\section{MATERIAL Y MÉTODOS}

El estudio consideró $100 \%$ de los titulados de la Carrera de Tecnología Médica en los años 1996 a 2001. La población estudiada se obtuvo por un censo de los egresados (178 en el periodo), en donde todos tenían la posibilidad de ser encuestados si eran localizados. Del total de egresados se logran contactar 148 de ellos que constituyen en definitiva la población objetivo. Responden a la solicitud de opinión un total de 82 egresados, que constituyen una muestra representativa al $95 \%$ de confianza con un error máximo permisible del $2,3 \%{ }^{12}$. Se utilizó el diseño de Investigación Descriptiva, de tipo transversal a fin de determinar las condiciones que contribuyen a dar respuesta a la problemática planteada. Se consideraron los aportes obtenidos de la aplicación del instrumento de recolección de datos diseñado para el estudio, que constituyó la principal fuente de datos. 
Figura 1. Representación de la escala usada para valorar en que medida las competencias fueron adquiridas durante la formación

\section{LEYENDA}

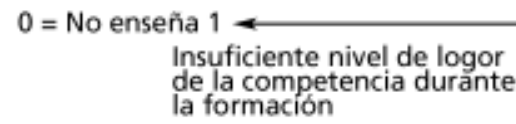

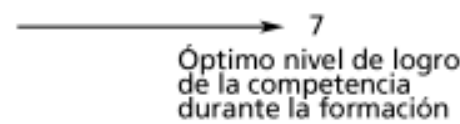

Optimo nivel de logro

durante la formación

Marque con una $X$ sobre el casillero o recuadro señalado según su apreciación atendiendo a la escala antes señalada

\begin{tabular}{|l|l|l|l|l|l|l|l|l|}
\hline COMPETENCIA AREA ASISTENCIAL & 0 & 1 & 2 & 3 & 4 & 5 & 6 & 7 \\
\hline Elaborar y evaluar curvas de calbración de ténicas espectrofotométricas & & & & & & & & \\
\hline
\end{tabular}

Etapa I: Construcción de un perfil de referencia basado en competencias profesionales, para la carrera de Tecnología Médica de la Universidad de Talca

Para la elaboración del perfil profesional, se conceptualizaron las competencias profesionales de acuerdo a la definición de la OIT, se revisaron los objetivos curriculares del programa de la Carrera de Tecnología Médica de la Universidad de Talca junto con recolectar sugerencias y opiniones del cuerpo académico de la Facultad a cerca de cual es el profesional que hoy en día se desea formar. Se analizaron los comentarios y pautas de evaluación que han hecho llegar Jefes de Laboratorios Clínicos y Servicios de Banco de Sangre de distintos Centros Asistenciales del país, que han sido utilizados a lo largo del tiempo, como campos clínicos para la realización del internado de los alumnos de Tecnología Médica de la Universidad de Talca. Con estos insumos se estableció un perfil profesional basado en competencias para la carrera de Tecnología Médica, de la Universidad de Talca. La estructura del perfil considera las áreas: asistencial, administrativa, investigación, docencia y personal social. Se sometió el perfil profesional a validación a través de juicio de expertos, estableciendo grado de congruencia a través del coeficiente de Serafine ${ }^{13}$.

\section{Etapa II: Construcción y Validación} del Instrumento aplicado a los egresados.

Para esta segunda etapa se definieron los aspectos a evaluar basándose en el perfil de referencia optimizado luego del análisis y opinión de los expertos y se elaboró un instrumento, tipo encuesta con Introducción, explicación y escala de respuestas, se validó sometiéndola a una prueba piloto, se optimizó el Instrumento para su reproducción y aplicación.
La encuesta definitiva estaba constituida por cinco áreas, cada una de ellas con un conjunto de indicadores o competencias, que variaba en número de acuerdo al área, (ver anexo) e incorporando al término de la misma un espacio para registrar observaciones a modo de comentarios o sugerencias de parte de los encuestados. Se les solicitó a los egresados que evaluaran en qué medida la formación entregada en la Universidad los había preparado en un conjunto de competencias basándose en el perfil de referencia. Los egresados debían responder de acuerdo a una escala de respuesta, que representa una evaluación en continuo, que transita desde una nula formación hasta un óptimo para cada una de las competencias. Como ejemplo se muestra la figura 1.

\section{Etapa III: Aplicación de la encuesta.}

Para contactar a los egresados se utilizaron los registros de titulación existentes, desde donde se obtuvo dirección y/o teléfono. Posteriormente se hizo un primer contacto telefónico con ellos, con el propósito de conocer su residencia actual y/o lugar de trabajo. Las encuestas fueron repartidas en forma personal o enviadas por correo a través de medio impreso y en algunos casos a través de medio electrónico. La encuesta fue autoaplicada. La recopilación de encuestas fue de un $55,4 \%$.

\section{Etapa IV : Metodología para el Análisis de Resultados.}

Para el análisis de los resultados, la escala de respuestas se codificó según el esquema que muestra la figura 2. La interpretación de los resultados de la investigación, se realizó a través del método estadístico porcentual y cálculo de la desviación estándar. El criterio para analizar los resultados obtenidos fueron categorías interpretativas. Estas fueron diseñadas 
Figura 2. Esquema de escala de respuestas y su codificación

\begin{tabular}{|c|c|}
\hline ESCALA & $\begin{array}{r}\text { GRADO } \\
\text { (CONCEPTO) }\end{array}$ \\
\hline 0 & BAJO \\
\hline 1 & \\
\hline 2 & MEDIO \\
\hline 3 & \\
\hline 4 & \\
\hline 5 & ALTO \\
\hline 6 & \\
\hline 7 & \\
\hline
\end{tabular}

tomando como referencia una escala de cuartiles y considerando los porcentajes obtenidos sólo en el nivel Alto, luego de realizada la codificación en base a la escala de respuestas mostrada en la figura 2. Las categorías consideradas se muestran en la figura 3.

\section{RESULTADOS}

Se procesaron un total de 82 encuestas, lo que corresponde a un $55,4 \%$ de los egresados contactados. Para el análisis de los resultados se sigue el orden de la estructura del perfil de referencia. Las tablas que se presentan indican la manifestación (en porcentaje) tomando en cuenta sólo el grado Alto de logro de la competencia, de acuerdo a la codificación de las respuestas mencionadas en la metodología, y se considera el promedio que se obtiene del total de los egresados e indicando la desviación estándar correspondiente a cada uno de ellos.

El Área Asistencial, considerada como el área que da el sello a la profesión, se divide en seis sub-áreas, correspondientes a las cinco especialidades que com-
Figura 3. Categorías interpretativas usadas como criterio de análisis

\begin{tabular}{|l|l|}
\hline $\begin{array}{l}\text { \% de egresados que } \\
\text { valora el logro de } \\
\text { la competencia en } \\
\text { nivel Alto }\end{array}$ & Categoría interpretativa \\
\hline Menos del $25 \%$ & Deficiente \\
\hline Entre $25 \%$ y $50 \%$ & Medianamente satisfactorio \\
\hline Entre $51 \%$ y $75 \%$ & Satisfactorio \\
\hline Más del $75 \%$ & Óptimo \\
\hline
\end{tabular}

prende la mención que dicta la Universidad de Talca para la carrera de Tecnología Médica y la número seis son aquellas competencias clínicas que son comunes para todas las sub-áreas.

Siguiendo el criterio de análisis en que se consideran las categorías interpretativas mencionadas en la metodología, tal como muestran los datos de la Tabla $\mathrm{N}^{\circ} 1$ se puede apreciar que los egresados consideran que las competencias logradas en las sub_áreas Banco de Sangre y Parasitología, se encuentran en un nivel óptimo. Las áreas Bioquímica Clínica, Hematología y Microbiología, de acuerdo a la categorización empleada se encuentran en el nivel satisfactorio (entre 51 y 75\%), aunque hay que destacar la marcada diferencia entre las dos primeras y Microbiología. El logro de las competencias consideradas comunes para todas las áreas se presentan en un nivel satisfactorio.

De todas las áreas de desempeño consideradas en el perfil: asistencial, administrativa, investigación, docencia y personal social, y siguiendo el mismo criterio de análisis, se presentan los resultados de todas

Tabla $N^{\circ}$ 1: Porcentaje promedio de manifestación de logro de las competencias en grado Alto durante la formación por sub-área clínica.

\begin{tabular}{l|cccccc}
\hline & \multicolumn{5}{|c}{ ÁREA ASISTENCIAL SUB ÁREAS } \\
\hline & Banco de Sangre & $\begin{array}{c}\text { Bioquímica } \\
\text { Clínica }\end{array}$ & Hematología & Microbiología & Parasitología & Comunes \\
& & & & 15 & 6 & 21 \\
$\mathrm{n}$ & 14 & 10 & 70.7 & 59.5 & 70.6 & 7.4 \\
Promedio & 85.9 & 70.7 & 5.5 & 7.9 & 3.9 \\
DS & 3.5 & 5.0 & 5.9 & & 7.9 \\
\hline
\end{tabular}

n, $N^{\circ}$ de competencias listadas para cada sub-área ; DS, desviación estándar. 
Tabla N²: Grado de manifestación de logro de la competencia (\%) de los alumnos durante la formación por Área y por año egreso.

\begin{tabular}{|c|c|c|c|c|c|c|c|c|c|c|c|c|c|c|c|}
\hline \multirow[b]{3}{*}{ AÑO } & \multicolumn{3}{|c|}{ ÁREA ASISTENCIAL } & \multicolumn{3}{|c|}{ ÁREA ADMINISTRATIVA } & \multicolumn{3}{|c|}{ ÁREA INVESTIGACIÓN } & \multicolumn{3}{|c|}{ ÁREA DOCENCIA } & \multicolumn{3}{|c|}{ ÁREA PERSONAL } \\
\hline & \multicolumn{3}{|c|}{$\mathrm{N}=80$} & \multicolumn{3}{|c|}{$\mathrm{N}=19$} & \multicolumn{3}{|c|}{$\mathrm{N}=10$} & \multicolumn{3}{|c|}{$N=5$} & \multicolumn{3}{|c|}{ SOCIAL $N=18$} \\
\hline & Baja & Media & Alta & Baja & Media & Alta & Baja & Media & Alta & Baja & Media & Alta & Baja & Media & Alta \\
\hline 1996 & 8.8 & 16.5 & 74.6 & 60.5 & 17.5 & 21.1 & 8.7 & 32.3 & 59.0 & 3.7 & 30.8 & 32.2 & 1.7 & 6.7 & 91.7 \\
\hline 1997 & 10.4 & 16.2 & 73.5 & 38.8 & 37.8 & 23.4 & 15.5 & 27.3 & 48.0 & 39.9 & 22.1 & 35.5 & 2.7 & 9.1 & 88.2 \\
\hline 1998 & 12.5 & 18.8 & 68.6 & 36.8 & 39.0 & 24.1 & 11.7 & 30.8 & 57.5 & 29.4 & 27.3 & 43.3 & 0 & 1.7 & 98.3 \\
\hline 1999 & 9.3 & 15.7 & 75.0 & 33.0 & 35.4 & 31.6 & 8.9 & 27.8 & 63.3 & 32.2 & 24.6 & 43.2 & 0.6 & 8.3 & 91.1 \\
\hline 2000 & 6.1 & 15.4 & 78.5 & 28.0 & 38.5 & 33.5 & 12.1 & 22.6 & 65.3 & 22.8 & 26.5 & 50.7 & 0.5 & 6.3 & 93.2 \\
\hline 2001 & 10.7 & 22.1 & 67.3 & 26.7 & 44.1 & 29.1 & 6.0 & 26.7 & 60.7 & 13.0 & 26.1 & 59.0 & 5 & 10 & 85.0 \\
\hline Prom & 9.6 & 17.5 & 72.9 & 37.3 & 35.4 & 27.1 & 10.5 & 27.9 & 59.0 & 23.5 & 26.2 & 44.0 & 1.8 & 7.0 & 91.3 \\
\hline DS & 2.2 & 2.6 & 4.2 & 12.3 & 9.2 & 5.0 & 3.3 & 3.4 & 6.1 & 13.3 & 2.9 & 9.8 & 1.9 & 3.0 & 4.5 \\
\hline
\end{tabular}

$\mathrm{N}$ = Número de competencias listadas en el perfil de referencia; DS, desviación estándar.

las categorías y por año de egreso a modo de tener una visión general. (Tabla $\mathrm{N}^{\circ} 2$ ).

En el área administrativa se listaron 19 competencias que debe poseer el Tecnólogo Médico. Los resultados demuestran que son las que se ubican en los niveles inferiores, no existiendo diferencia según años de egreso. Para el área investigación se listaron 10 competencias como base para realizar estudios orientados a generar nuevos conocimientos. En cuanto a las competencias deseables para cumplir con una función docente, se consideraron 5 competencias que tienen relación con la participación y colaboración en actividades de capacitación, supervisión, educación a la comunidad. Finalmente en cuanto a las competencias del área personal - social que dicen relación con el saber ser, las actitudes, el desarrollo personal, el actuar éticamente, etc., la formación es percibida en el nivel más alto, por lo que se presenta como una fortaleza de la formación dada.

El instrumento consideraba un espacio "OBSERVACIONES" incorporado al término de la encuesta. Estas fueron categorizadas, recurriendo a identificar segmentos de frases reales escogidas según un criterio como representador del texto y atendiendo a la naturaleza de las mismas y se agruparon en tres dimensiones. El primer grupo, son comentarios que apoyan la iniciativa de evaluar la gestión educativa y completar la malla curricular en áreas deficientes y de agradecimientos por la formación entregada en las cuales los encuestados se sienten satisfechos y orgullosos de ser egresados de la Universidad de Talca. Un segundo grupo, son los comentarios atribuibles a las debilidades que reconocen en su formación, que en un alto número de egresados son deficiencias en herramientas de administración, lo que los hace estar en desventaja frente a otros profesionales de la salud. Algunos manifiestan que dentro del área asistencial su preparación no es igualmente sólida en todas las sub-áreas. El tercer grupo, son los comentarios hechos a modo de sugerencias y aquí se halló referencias a: Crear base de datos de egresados con el propósito de contactarlos cuando se realicen cursos o postgrados, dar mayor herramientas en el área administrativa y por último considerar el área ventas como desempeño profesional y dar herramientas para ello.

\section{DISCUSIÓN}

El presente trabajo, cuyo objetivo principal ha sido conocer la auto percepción que tienen los egresados del logro de las competencias profesionales durante su formación, tomando como referencia un perfil profesional basado en competencias, establecido en la primera etapa de este estudio, para la carrera de Tecnología Médica de la Universidad de Talca, con el propósito de hacer un diagnóstico de la situación actual, como punto de partida, y con esta información evaluar la formación entregada. Se discuten los principales resultados, por área de desempeño.

En el área Administrativa, atendiendo a los resultados, en que aparece como la más débil dentro de la formación, información que es avalada por los comentarios de los egresados, en que reconocen deficiencias en herramientas de administración y muestran su preocupación por la desventaja que poseen frente a otros profesionales de la salud, aspectos que hacen concordantes los resultados obtenidos en la encuesta. La opinión de los egresados que manifiestan la necesidad de fortalecer el área de administración, conlleva a analizar si se hace necesario incorporar en los planes y programas de estudio más herramientas de administra- 
ción, de tal forma que tenga suficiente competencia en esta área al término de su formación profesional, o si debe ser considerada para cursos de especialización o estudios de posgrado. La implementación de la gestión de calidad en los sectores hospitalarios y ambulatorios conducirá a la puesta a punto de sistemas de gestión, que serán los ejes principales de los futuros desarrollos, por lo que se justifica fortalecer la formación en ámbitos de administración y gestión de Laboratorios Clínicos y Servicios de Bancos de Sangre.

En relación con la actividad de investigación, aún cuando los egresados manifiestan haber desarrollado las competencias en un nivel satisfactorio, lleva al cuestionamiento en relación a si éstas, deben formar parte de los dominios centrales de la formación, o ser considerados como dominios de competencias no críticos para el ejercicio, por lo que para alcanzar el nivel óptimo de las competencias, correspondería que se logren mediante estudios posteriores o esfuerzos personales.

Para el área Docente, las competencias consideradas en el perfil de referencia, dicen relación con actividades de capacitación al personal, supervisión, educación a la comunidad, todas necesarias para responder a las necesidades que con lleva la reforma de la Salud $^{14}$, en que privilegia la salud primaria, considerando un cambio desde el enfoque curativo hacia uno con mayor énfasis en lo educacional y preventivo, con mayor presencia en la comunidad, por lo que a los profesionales del equipo de salud, se les exigirá una mayor participación en cuanto a prevención y promoción, incentivando la educación en los diversos sectores poblacionales, generando una actitud activa de los participantes, no sólo para convertirse en su propio agente de salud sino además, para promoverse como agente comunitario. Otro aspecto a considerar, es que, es necesario asesorar e implementar programas de educación en salud, dirigidos a otros profesionales o a reforzar la capacitación continua para la actualización de los profesionales del área. Los resultados medianamente satisfactorios obtenidos en esta área, alertan a que se debe hacer un replanteamiento y una revisión de la formación con el fin de entregar más herramientas al egresado que le permita lograr un nivel de competencia adecuado para enfrentar este nuevo escenario.

El área personal social, aparece como la gran fortaleza dentro de la formación, en forma global el 91,3 $\%$ de los egresados manifiestan haber logrado las competencias en un grado alto. A esta área corresponden las competencias que dicen relación con los principios éticos y deontológicos, con una formación fundamental orientada a mantener permanentemente el desarrollo personal y profesional, a la forma en que el profesional se relaciona con el mundo social, con la cultura organizacional, con el trabajar en equipo, con lograr un compromiso genuino frente a los usuarios, a su especialidad, a la institución donde labora y al país. Las exigencias del mundo actual y los cambios que en él ocurren, hace necesario enfatizar en la formación de criterios y valores, con el fin de asegurar que el egresado cumplirá fehacientemente con los principios de la deontología profesional. Si bien esta área aparece muy bien evaluada, se debe seguir fortaleciendo.

El área Asistencial es aquella en donde se centra el dominio principal de la profesión, por lo que aquí encontramos las competencias centrales que la identifican. Como ya se mencionó, ésta se divide en seis sub-áreas, las cinco primeras correspondientes a la mención "Laboratorio Clínico, Hematología y Banco de Sangre", que es la que dicta la Universidad de Talca para la carrera de Tecnología Médica y la sexta en donde se ubicaron aquellas competencias clínicas que son comunes para todas las sub-áreas. Para mayor claridad, se discute cada una de las áreas por separado.

Sub-área Banco de Sangre: los resultados indican que un $85,9 \%$ de los egresados manifiestan haber logrado las competencias en un nivel óptimo. Si bien es cierto que los resultados son bastante buenos, de igual forma se debe revisar el programa curricular, puesto que habrá un cambio de escenario para los futuros egresados dado que las Unidades de Bancos de Sangre del país se encuentran en plena reorganización, en donde se pretende cambiar el sistema actual por un sistema centralizado en base a grandes Centros de Sangre o Hemocentros y Unidades de Medicina Transfusional. Por este motivo se estipula en materia de Recursos Humanos la incorporación de profesionales con el perfil necesario para la gestión de la red de Centros de Sangre y Unidades de Medicina Transfusional, con competencias tales como, gerencia de Centros de Sangre; desarrollo de sistema de información, marketing social, gestión de stock ${ }^{15}$. Con seguridad se aproxima en esta área una tarea desafiante, ya que implica para los profesionales en desempeño, modificar las actuales prácticas y para las escuelas formadoras de profesionales, adecuar el currículo a los nuevos requerimientos.

Sub-área Bioquímica Clínica: Los egresados manifiestan buena percepción de su formación en esta área. Si bien en forma general el promedio $70,7 \%$ 
indica que los egresados manifiestan un logro de las competencias en un nivel satisfactorio, al hacer un análisis detallado de cada una de las competencias en su mayoría son logradas en un nivel óptimo. La excepción la hacen tres que aparecen en un nivel satisfactorio y son la causa de que el promedio general se presente bajo el $75 \%$. Es importante hacer notar que para las competencias que se relacionan con el quehacer de rutina del profesional que ejerce en un laboratorio clínico, los egresados han manifestado un grado Alto de logro, y aquellas que se encuentran en grados inferiores, se relacionan con el estudio de algunos líquidos biológicos específicos, que forman parte de la especialización y por lo tanto sería muy ambicioso esperar que los niveles de competencia óptimos sean obtenidos en el pre-grado.

Bioquímica Clínica le entrega a los estudiantes las herramientas fundamentales para integrar las bases teóricas de la Química analítica y su interpretación con la clínica. Por la relevancia que esta área tiene en la formación profesional del Tecnólogo Médico, por la responsabilidad de la Universidad de entregar a la sociedad un profesional con las competencias centrales de la profesión y dada la velocidad de cambio con que el entorno se va presentado, es que debe ser evaluada constantemente, de tal forma de ajustar los programas de acuerdo a los requerimientos dinámicos del mundo el trabajo.

Sub-área Hematología: Fue evaluada con un promedio general de un $70,7 \%$, que como se ha señalado, representa el promedio de egresados que manifestaron haber logrado en grado alto las competencias establecidas en el perfil de referencia para esta área. De manera específica se observa que existe una buena valoración de las competencias necesarias para la realización de las metodologías para contribuir a la prevención, diagnóstico y seguimiento terapéutico de gran parte de las patologías hematológicas. Manifiestan debilidad en algunas de ellas y sería importante evaluar si deben ser consideradas necesarias en un contexto de desempeño regular o si corresponden a uno de mayor complejidad, ya que esto influye de manera decisiva en los énfasis que se les dé, dado los diferentes dominios de competencia que involucra la profesión.

Sub-área Microbiología: Por los resultados obtenidos para esta sub-área, en la que en promedio un 59,5 $\%$ de los egresados manifiestan haber logrado las competencias en un nivel óptimo, aparece como la más débil dentro del área asistencial. Sin embargo, se debe destacar que aquellas competencias que tienen relación con el trabajo de rutina de un Laboratorio de
Microbiología, se manifiestan en el nivel óptimo. Microbiología resulta ser un área muy amplia, aborda: la bacteriología, micología y virología; por lo que los alumnos durante su formación deben aprender una gran variedad de contenidos, como así mismo desarrollar muchas habilidades de criterio diagnóstico, aplicación de algoritmos, interpretación de datos derivados de observaciones en relación con la teoría apropiada, entre otras. Es aquí en donde se requiere una exhaustiva revisión del currículo, con el propósito de definir a que nivel de generalidad/especificidad se desarrollarán los contenidos troncales de la formación.

Sub-área Parasitología: Los egresados manifiestan en promedio un nivel óptimo de logro de las competencias de esta área $(83,4 \%)$. Evidentemente esto no significa que no deba hacerse una revisión del curriculo, puesto que han aparecido nuevos escenarios clínicos, tales como, la aparición de cuadros clínicos de parasitosis oportunistas derivados de la depresión o supresión inmunitaria de los pacientes, las variaciones ecológicas, etc. lo que se traduce en la presentación de parasitosis emergentes, que deben ser abordados en las escuelas formadoras de profesionales. También el avance de la biología molecular, en alianza con la bioquímica y la inmunología, abre posibilidades ilimitadas en el diagnóstico y tratamiento en esta área, en la que las nuevas generaciones de profesionales se verán enfrentados, por lo que aquí se impone una readecuación de los programas de estudio.

Competencias comunes a todas las sub-áreas clínicas: Los resultados señalan en promedio una manifestación de logro en grado alto en un 70,6 \% de los egresados. Aquí se especifican aquellas competencias que son necesarias para el desempeño del profesional, independiente de la sub-área que labore. Entre ellas están aquellas competencias relacionadas con la bioseguridad, toma de muestras, preparación de reactivos, etc., las que resultan evaluadas muy bien por los egresados. También en este grupo se encuentran las competencias relacionadas con técnicas de biología molecular, las que aparecen con los resultados más deficientes. Para discutir estos resultados hay que hacer notar que el grupo en estudio lo comprenden egresados entre los años 1996 a 2001, años en que aún la formación en esta área era a nivel de conocimiento, sin pretender un especial dominio de las competencias y aunque se sabe que la Biología Molecular es parte del presente y futuro de la profesión, la mayoría de los profesionales en ejercicio no ha recibido formación. Es por ello que a las nuevas generaciones se les debe fortalecer. 
Finalmente, dado que el planteamiento de este estudio tuvo como propósito hacer un diagnóstico en base a un perfil profesional basado en competencias, sobre la valoración de la formación profesional recibida por los Tecnólogos Médicos egresados de la Universidad de Talca, y aportar con esta información, para apoyar la toma de decisiones y la planeación académica relacionada con el contenido curricular y el rediseño de los programas de estudio, se pueden extraer las siguientes conclusiones:

Con relación a la calidad de la formación profesional expresada mediante la autoevaluación de los egresados sobre las competencias profesionales adquiridas, éstos valoran positivamente las capacidades y destrezas adquiridas en su formación en el área asistencial, aún cuando manifiestan algunos indicadores deficientes, lo que supone sería conveniente tomar medidas necesarias en función de mejorar la calidad de la formación brindada. Para el área investigación, la valoración fue satisfactoria y para las áreas docencia y administrativa medianamente satisfactorias, siendo está última considerada la más débil. Con esto se puede concluir que no les ha brindado el nivel necesario para desempeñarse eficientemente en esta área, lo que se podría traducir en una desventaja frente a otros profesionales de la salud. Hay alta valoración de la formación personalsocial, lo que pone en manifiesto que las competencias entregadas en ésta, se han privilegiado tanto como las profesionales, lo que está acorde con las nuevas concepciones acerca del rol y sentido de la universidad en interacción con el mundo actual, y que debe reflejarse en la formación.

Para la interrogante planteada acerca si el currículo vigente de la carrera permite que los estudiantes logren las competencias establecidas en el perfil, se concluye que si bien es cierto es adecuado para asegurar el logro de gran número de competencias, éste se debe revisar con el objetivo de incorporar contenidos para el logro de aquellas deficientes y actualizar otros, para estar acorde con los avances científicos tecnológicos en la perspectiva de mejorar permanentemente la calidad de la formación brindada a objeto de entregar personas competentes en la función a desempeñar en concordancia con la demanda actual y no apostar a que las carencias iniciales serán suplidas con la experiencia.

\section{AGRADECIMIENTOS}

El presente trabajo surge de la tesis realizada, para optar al grado académico de Magister en Salud
Pública con mención en Administración en Salud. Facultad de Ciencias de la Salud de la Universidad Católica del Maule - Talca, Chile. 2004. Mis agradecimientos al Prof. Raúl Fuentes F. Dr. en Educación, por su amabilidad, apoyo y dedicación que le impuso la supervisión de la tesis. A los egresados que respondieron a la encuesta, material sin el cual este estudio no podría haber sido realizado.

\section{BIBLIOGRAFÍA}

1. Breedlove, C.; Hedrick, H. Reenvisioning Medical Education for the New Millennium. JAMA, 1999; 282: 84 -92.

2. INEM. Metodología para la Ordenación de la Formación Profesional Ocupacional. Madrid.1995

3. González, J., Wagenaar,R. Eds. Tuning Educational Structures in Europe. Informe Final. 2003.

4. II Conferencia Panamericana de Educación en Salud Pública: Reforma Sectorial y Funciones Esenciales de Salud Pública. Desafíos para el Desarrollo de Recursos Humanos. Mex. DF. 1998.

5. Posner, G. Análisis de curriculo. Mc Graw Hill. Colombia.1998.

6. Amat salas, O.; Puig Pla,X. Situación actual de la Universidad y de sus relaciones con las empresas. Rev. Alta Calidad, 1999; 35; 208:515-523.

7. Gago, A. (2000). El CENEVAL y la evaluación externa de la educación en México. Revista Electrónica de Investigación Educativa, 2 (2). Consultado el 15 de enero de 2007 en: http://redie.uabc.mx/vol2no2/contenido-gago.html

8. Lave, J. Cognition in Practice. Cambridge University Press. Cambridge.Mass.1988

9. Cruz, P. Rojas, S. Vega, G., Villegas, Y. El capital humano y la gestión por competencias. Universidad de Antofagasta. Facultad de Educación.

10.Bunk, G. P. La transmisión de las competencias en la formación y perfeccionamiento Profesional de la RFA. Rev. europea de Formación Profesional. 1994; 1; 8-14.

11. XIX Conferencia de la Asociación Latinoamericana y del Caribe de Educación en Salud Pública. Desarrollo de la Educación en Salud Pública: Desafíos para el siglo XXI. De la realidad a las disciplinas: Estructuración de las respuestas educacionales con Base en las Competencias de las Instituciones y de la Fuerza de Trabajo. OPS. 2000.

12.Hernández S,R; Fernández C.C. Metodología de la Investigación. $2^{\circ}$ Edición. Mc Graw Hill Editores S.A, 2000.

13. Serafine, D. Coeficiente de congruencia simple. Organización de los Estados Americanos (OEA).1981.

14. Quiroga R. Regulación de recursos humanos de salud en Chile. Publicaciones. Minsal/OPS, 2000.

15. Amaya S., Astorga I. Proyecto de Regionalización de Bancos de Sangre. 1998. Depto. de Desarrollo Red Asistencial, Ministerio de Salud, Enero 1999. Consultado el 15 de julio de 2004 en: http://www.ias-uchile.cl/files/biblioteca/BancosdeSangre.pdf. 


\section{ANEXO \\ Lista de competencias por área de desempeño usadas como indicadores para valorar la formación recibida.}

\section{ÁREA CLÍNICA}

ÁREA CLINICA SUB AREA BANCO DE SANGRE:

COMPETENCIAS

1 Capacidad de seleccionar o excluir donantes de sangre a través de técnicas de entrevistas y examen físico.

2 Realizar proceso de flebotomía.

3 Reconocer y tratar accidentes y complicaciones ocurridas durante la donación de sangre.

4 Preparar diferentes hemocomponentes.

5 Conocer los principios de la aféresis.

6 Realizar exámenes inmunohematológicos a donantes y receptores.

7 Manejar técnicas de screenning destinadas a la detección de enfermedades infecciosas transmisibles por transfusión.

8 Realizar detección y prevención de aloinmunización.

9 Realizar la terapia transfusional en adultos y niños.

10 Realizar vigilancia postransfusional.

11 Realizar control de calidad de hemocomponentes.

12 Seleccionar sangre a usar en transfusiones intrauterinas y recambio sanguíneo

13 Realizar técnicas destinadas al diagnóstico pre y posnatal de la EHRN.

14 Aplicar normas de control de calidad al trabajo rutinario de un laboratorio clínico y servicio de banco de sangre.

ÁREA CLINICA SUB AREA BIOQUÍMICA CLINICA:

\section{COMPETENCIAS}

Realizar exámenes diversos en sangre, suero, orina y otros líquidos biológicos. Medir e interpretar diversos parámetros bioquímicos que evalúan la función de los distintos sistemas del organismo:

1 Función renal y equilibrio ácido-base (equilibrio de compuestos nitrogenados no proteicos, etc.) electrolítico

2 Función hepática (bilirrubina, proteínas plasmáticas carbohidratos, lípidos).

3 Diagnóstico enzimático( en infarto al miocardio, hepatopatías, enfermedades pancreáticas, renales y musculares)

4 Metabolismo de calcio, fósforo y magnesio.

5 Función pancreática (exocrina y endocrina)

6 Mecanismos de acción hormonal. (hormonas esteroidales y de regulación hipofisiarias)

7 Líquidos biológicos. (LCR, Amniótico)

8 Líquidos biológicos. (Pleural, seminal, articular)

9 Relacionar los resultados de los análisis de laboratorio con diversas patologías.

10 Elaborar y evaluar curvas de calibración de diferentes técnicas espectrofotométricas.

ÁREA CLINICA SUB AREA HEMATOLOGÍA:

\section{COMPETENCIAS}

1 Reconocer la fisiopatología de la hematopoyesis. Realizar e interpretar diferentes técnicas hematológicas diagnósticas:

2 Microhematocrito.

3 Hemoglobina.

4 Hemogramas.

5 Exámenes básicos de hemostasia.

6 Exámenes para estudio de Trombocitopenias.

7 Cuantificación de factores de la coagulación.

8 Control tratamiento anticoagulante oral y heparina.

9 Uso de contadores celulares.

10 Identificar e interpretar alteraciones citológicas en sangre periférica.

11 Reconocer la fisiología y patología de las diferentes etapas de la hemostasia.

12 Reconocer y diagnosticar las discrasias de células plasmáticas, síndromes mielo displásticos.

13 Realizar control de calidad en un laboratorio de hematología.

14 Interpretar los hallazgos fundamentales del mielograma.

\section{ÁREA CLINICA SUB AREA PARASITOLOGÍA:}

\section{COMPETENCIAS}

1 Reconocer taxonomía, ciclo biológico y cuadros clínicos provocados por parasitosis humanas.

2 Realizar profilaxis de parasitosis humanas.

3 Realiza técnicas que le permiten diagnosticar parasitosis en humanos.

4 Reconocer elementos micro y macroscópicos para diagnóstico parasitológico en humanos.

5 Realizar métodos de diagnóstico directo e indirecto de parasitosis.

6 Identificar microscópicamente protozoos.

ÁREA CLINICA SUB AREA MICROBIOLOGÍA

\section{COMPETENCIAS}

1 Realizar las diferentes técnicas utilizadas para el diagnóstico de diversas enfermedades infecciosas con destreza.

2 Reconocer nomenclatura, conceptos básicos de farmacocinética y los principios de uso de fármacos en terapia.

3 Aplicar conocimientos de la taxonomía del mundo microbiano.

4 Reconocer morfología, ultra estructura, procesos nutritivos, metabólicos de bacterias y hongos.

5 Reconocer morfología, ultra estructura, replicación, poder infectivo de los virus.

6 Tomar muestras microbiológicas.

7 Preparar y manejar diversos medios de cultivo.

8 Aislar e identificar especies bacterianas de diversas muestras clínicas patológicas.

9 Realizar exámenes bacteriológicos de muestras de pus de heridas, secreciones, líquido cefalorraquídeo, sangre, orina, deposición y otros

10 Aislar e identificar hongos patógenos para el ser humano.

11 Realizar exámenes micológicos de diversas muestras clínicas de pacientes.

12 Realizar diagnóstico microbiológico de las enfermedades infecciosas causadas por bacterias, hongos y virus que afectan al ser humano.

13 Realizar técnicas serológicas de diagnóstico de infecciones virales.

14 Realizar técnicas de Inmunofluorecencia para diagnóstico de infecciones virales.

15 Participar en el control de las infecciones intrahospitalarias.

ÁREA CLINICA COMUNES A TODAS LAS SUB AREAS:

1 Determinar y evaluar los signos vitales de un individuo.

2 Otorgar atención de primeros auxilios con fundamento científico.

3 Aplicar técnicas de enfermería para utilizarlas en el trabajo clínico.

4 Manipular muestras biológicas con destreza

5 Hacer análisis de instrumentos de uso rutinario en los Laboratorios clínicos con habilidad y destreza 
6 Calibrar y utilizar instrumentos y equipos de uso corriente en un Laboratorio Clínico.

7 Interpretar los resultados de una muestra clínica.

8 Preparar Reactivos para análisis biológicos.

9 Tomar muestras biológicas para realización de exámenes

10 Reconocer el tipo de examen a realizar según diagnóstico de la enfermedad.

11 Identificar la etiología y patogenia de las principales enfermedades que se producen en el organismo.

12 Realizar controles de calidad interno del trabajo de un laboratorio, aplicando distintas metodologías, como parte de un proceso de "sistema de calidad continua"

13 Interpretar los fenómenos fisiopatológicos del sistema inmune.

14 Preparar reactivos hematológicos.

15 Realizar exámenes por métodos de ELISA.

16 Realizar extracción de DNA.

17 Realizar amplificación de DNA por técnicas de PCR.

18 Realizar electroforesis en gel de poliacrilamida.

19 Aplicar Normas de bioseguridad.

20 Administrar correctamente tratamientos por vía parenteral e intramuscular.

21 Aplicar medidas básicas de protección laboral (fluidos orgánicos de alto riesgo, químicos, asepsia y antisepsia).

\section{ÁREA ADMINISTRACION:}

\section{COMPETENCIAS}

1 Reconocer los conceptos básicos de gestión en administración, como componentes fundamentales del funcionamiento de una organización del área de la salud.

2 Reconocer los principios de la administración, y valorar la importancia de una adecuada organización y control en base a criterios de eficiencia y eficacia.

3 Procesar información del entorno social y de los indicadores de gestión.

4 Administrar una sección de un Laboratorio clínico o Servicio de Banco de sangre.

5 Hacer un presupuesto operacional de una sección de un Laboratorio clínico y Servicio de Banco de Sangre.

6 Describir organigramas y funciones del personal de un Laboratorio Clínico y Servicio de Banco de Sangre.

7 Formular las normas que definen la orientación que deben tener las acciones que deben seguir cada uno de los miembros de un Laboratorio y/o Servicio de Banco de Sangre.

8 Implementar sistemas de evaluación y control para: eficiencia del desempeño, satisfacción del usuario y estímulo para retroalimentación y motivación permanente.

9 Aplicar los procedimientos y normas de la planificación estratégica, con una visión pro-activa de su entorno, y en concordancia con la misión del lugar de trabajo.

10 Aplicar técnicas de trabajo en equipo.

11 Planificar, ejecutar y evaluar la aplicación de técnicas y exámenes destinados al diagnóstico y a la terapia.

12 Programar actividades administrativas en servicios, programas o proyectos de la especialidad, incluyendo actividades de asesoría y auditoria médica

13 Manejar los recursos existentes en el Laboratorio para satisfacer las necesidades clínicas del lugar de trabajo.

14 Manejar bases de datos de pacientes.

15 Aplicar normas nacionales de planificación ejecución y evaluación de un programa de control de calidad interno y externo.

16 Resolver en forma armoniosa conflictos organizacionales, en un ambiente de justicia y equidad.

17 Realizar auditorías internas.

18 Manejar con destreza los programas informáticos relacionados con las nuevas tecnologías aplicadas a la gestión.

19 Manejar e interpretar información en redes computacionales intralaboratorio.

\section{ÁREA INVESTIGACIÓN:}

\section{COMPETENCIAS}

1 Manejar las técnicas y herramientas del método científico.

2 Elaborar proyectos de nivel básico de investigación de interés de la especialidad.

3 Realizar trabajos de investigación de nivel básico, de acuerdo a estándares del método científico.

4 Elaborar el informe final de una investigación.

5 Exponer temas en público.

6 Presentar experiencias relacionadas con la especialidad en reuniones clínicas, seminarios o congresos.

7 Aplicar técnicas básicas epidemiológicas para evaluar la situación de salud de una comunidad.

8 Utilizar los sistemas de medición en salud pública.

9 Participar activamente en trabajos de equipo multidisciplinarlo.

10 Asumir con responsabilidad, creatividad y flexibilidad, los retos de la tecnología y la generación de nuevas tecnologías.

\section{ÁREA DOCENCIA: COMPETENCIAS}

1 Participar y colaborar en actividades de capacitación, educación médica continua y en eventos científicos de la especialidad.

2 Formular planes de capacitación dirigidos al personal auxiliar de un Centro Asistencial.

3 Supervisar y evaluar pedagógicamente el trabajo asistencial.

4 Participar en actividades educativas dirigidas a pacientes y familiares, en acciones básicas de Salud Pública.

5 Participar en actividades educativas dirigidas a estudiantes de pre grado durante sus prácticas o Internado Clínico en Centros Hospitalarios o Laboratorios privados.

\section{ÁREA PERSONAL SOCIAL:}

COMPETENCIAS

1 Valorar la salud como componente esencial del nivel de vida, juzgando las distintas influencias y aplicando técnicas para preservarla.

2 Actuar ética y moralmente con el mayor respeto por la vida humana.

3 Actuar en concordancia con el Código de ética y deontología del Colegio de Tecnólogos Médicos de Chile.

4 Aplicar normas y disposiciones legales en el ámbito de la salud.

5 Actuar en conciencia de la importancia, honestidad, veracidad y ética en el trabajo de laboratorio.

6 Demostrar seguridad y confianza en el ejercicio de la profesión.

7 Demostrar responsabilidad en sus actos, guiado por un claro sentido de ética profesional, de equilibrio emocional, de equidad social y de un amplio espíritu crítico.

8 Asumir sus funciones on un alto sentido de celo profesional, con perspectivas de crecer permanentemente, pro-activo y enérgico en los planes y metas previstos.

9 Facilitar el desarrollo institucional, respetando y haciendo respetar normas establecidas.

10 Concebirse a sí mismo en el contexto de una formación permanente, con amplia sensibilidad a los cambios, con un espíritu de superación profesional constante y una actitud de investigador.

11 Valorar el trabajo en equipo.

12 Participar en actividades de promoción y mantenimiento de la salud.

13 Demostrar actitud crítica y auténtica que le permita evaluar con objetividad su trabajo y proyecciones, así como el de su equipo.

14 Demostrar aptitud para integrarse al equipo de salud.

15 Demostrar capacidad y actitud para continuar y profundizar su autoformación.

16 Contribuir a un adecuado clima organizacional en el entorno del trabajo.

17 Demostrar solidaridad y actitud de servicio, como corresponde a un profesional de la salud.

18 Propiciar en el ambiente laboral el estímulo a la superación disciplinaria y a la integración interdisciplinaria de las distintas áreas de la especialidad. 